\title{
Printed Organic Transistor-based Biosensors for Non-invasive Sweat Analysis
}

\author{
Kuniaki Nagamine, ${ }^{\dagger}$ Ayako Nomura, Yusuke IChImura, Ryota IzaWa, Shiori SaSAKI, \\ Hiroyuki Furusawa, Hiroyuki Matsui, and Shizuo ToKITo ${ }^{\dagger}$
}

Research Center for Organic Electronics (REOL), Yamagata University, 4-3-16 Jonan, Yonezawa, Yamagata 992-8510, Japan

\begin{abstract}
This review describes recent advances in biosensors for non-invasive human healthcare applications, especially focusing on sweat analysis, along with approaches for fabricating these biosensors based on printed electronics technology. Human sweat contains various kinds of biomarkers. The relationship between a trace amount of sweat biomarkers partially partitioned from blood and diseases has been investigated by omic analysis. Recent progress in wearable or portable biosensors has enabled periodic or continuous monitoring of some sweat biomarkers while supporting the results of the omic analysis. In this review, we particularly focused on a transistor-based biosensor that is highly sensitive in quantitatively detecting the low level of sweat biomarkers. Furthermore, we showed a new approach of flexible hybrid electronics that has been applied to advanced sweat biosensors to realize fully integrated biosensing systems wirelessly connected to a networked IoT system. These technologies are based on uniquely advanced printing techniques that will facilitate mass fabrication of high-performance biosensors at low cost for future smart healthcare.
\end{abstract}

Keywords Sweat analysis, printed electronics, organic transistor-based biosensor, flexible hybrid electronics

(Received September 22, 2019; Accepted December 25, 2019; Advance Publication Released Online by J-STAGE January 3, 2020)

1 Introduction: Biosensors for Non-invasive Personal Medical and Healthcare Applications

2 Transistor-based Biosensors for Highly Sensitive Sweat Analysis

3 Sweat Biomarkers and Their Collection/Detection Techniques
291

292

4 Advanced Printed Biosensor Systems Based on Flexible Hybrid Electronics (FHE) 297

5 Conclusions 299

6 Acknowledgements 299

7 Ethical Approval 299

8 References 299

\section{Introduction: Biosensors for Non-invasive Personal Medical and Healthcare Applications}

The concept of the Internet of Things (IoT), which connects objects to a network via various types of sensors to solve global societal needs, is now spreading to various application fields to achieve an emerging "smart lifestyle". Healthcare is one of the most attractive applications of IoT, because it provides various healthcare services for individuals, including daily health monitoring, fitness support, and elderly care. To realize these applications, there is a need to develop simple portable sensor devices that can be used anywhere, including non-medical

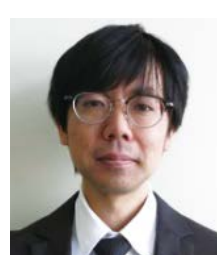

Kuniaki Nagamine received his Ph. D. degree in 2007 from Tohoku University. From 2007 to 2008, he was a staff of Central Research Laboratory, Hitachi, Ltd. He joined research group at Tohoku University (2008 - 2016). From 2017, he became Associate Professor of Yamagata University. His research area includes development of the electrochemical biosensors for physiological analysis.

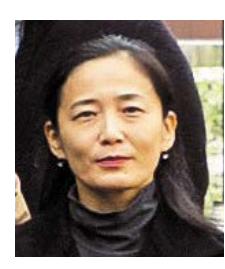

Ayako Nomura is working at Research Center for Organic Electronics (ROEL) of Yamagata University as Technical Assistant. Her research interest is development of the affinity-based electrochemical biosensors.

† To whom correspondence should be addressed.

E-mail: nagamine@yz.yamagata-u.ac.jp (K. N.); tokito@yz. yamagata-u.ac.jp (S. T.) 


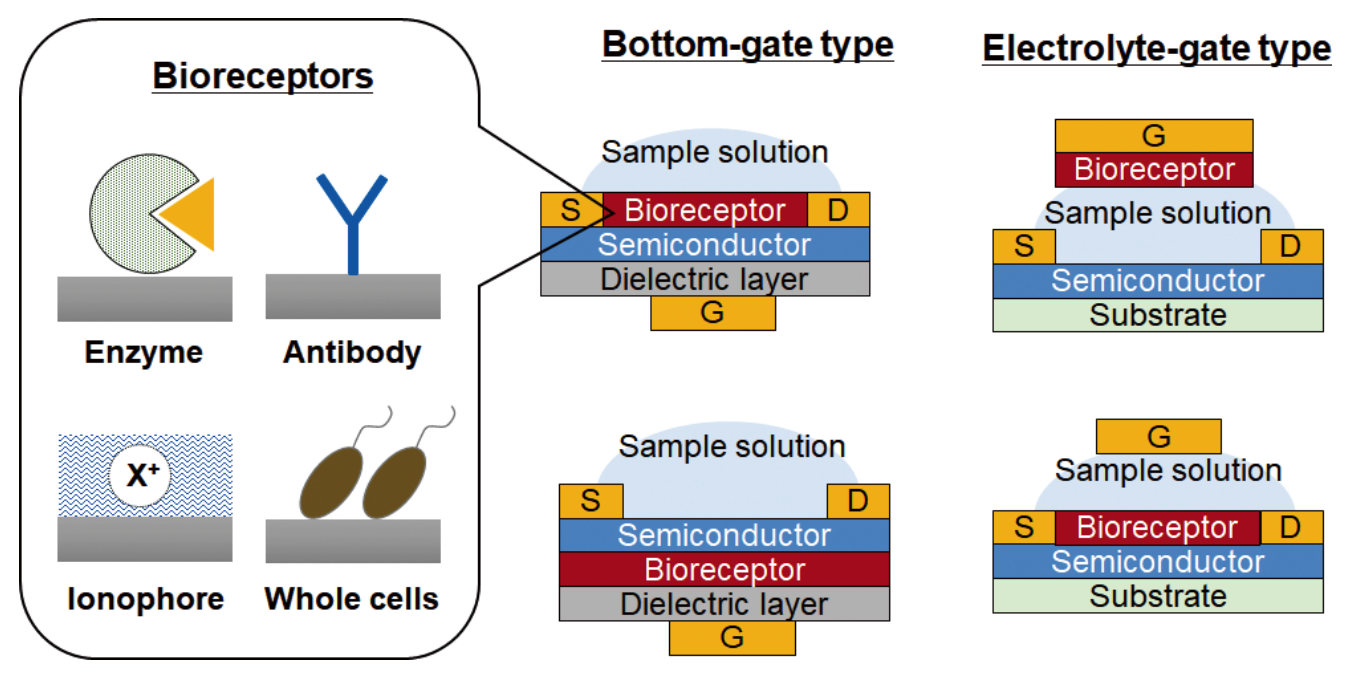

Fig. 1 Electrolyte-gate and bottom-gate type transistor-based biosensor structures.

institutions such as homes, offices, and nursing homes. This will allow for monitoring of human health conditions in real time and in a non-invasive manner. Some of these requirements are realized in advance by various types of vital physiological sensors. ${ }^{1,2}$

A biosensor is an analytical device composed of biological receptors connected to signal transducers. The biological receptors include enzymes, antibodies, nucleic acids (DNA, RNA, aptamer), ionophores, and the whole cell. Owing to the high selectivity of these biological receptors against analytes (even in complex bodily fluids), they have been successfully applied in the medical field for the diagnosis of physiological diseases. Recently developed microfabrication technologies based on photolithography and printing techniques have enabled the integration of biosensing elements into small and portable devices, thereby creating an opportunity to apply these devices in periodic medical and healthcare tests such as point-of-caretesting (POCT) and bed-side physical examinations. ${ }^{3-6}$ A representative commercial portable biosensor is a blood glucose sensor for diabetic patients. Moreover, the appearance of mechanically and chemically biocompatible materials accelerates the development of on-skin (wearable), ${ }^{7-14}$ ingestible, ${ }^{15}$ and implantable biosensors ${ }^{16-18}$ for real-time monitoring of physiological conditions. Developments in Internet technology allows for the wireless collection of biological data obtained through a network and their utilization in big data analyses for future advanced medical and healthcare applications.

Non-invasive diagnosis using externally secreted bodily fluids can be conducted with little physical burden and has been promoted as an alternative to blood-based diagnosis to achieve future personalized healthcare for patients as well as to maintain the well-being of healthy individuals and the elderly. Urine analysis has been traditionally conducted as a standard noninvasive health checkup of kidney function, hepatic disease, and diabetes. ${ }^{19}$ Furthermore, omics analyses have recently revealed that externally secreted biological fluids from the human body such as tears, saliva, and sweat also include biomarkers that are slightly partitioned from the blood. ${ }^{20,21}$ These external bodily fluids can be sampled in a non-invasive manner, thereby enabling daily self-monitoring of physiological conditions without uncomfortable and invasive blood sampling. For example, salivary amylase, cortisol, $\mathrm{NO}_{3}{ }^{-}$, and chromogranin $\mathrm{A}$ are considered to be indicators for mental stress that express the activity of the sympathetic nervous system, ${ }^{22,23}$ while some salivary proteins, metabolites, and microRNAs are considered to be biomarkers for various types of cancers. ${ }^{24-26}$ Tears are another example as they can include biomarkers that indicate diseases such as diabetes and cancer. ${ }^{27,28}$ Moreover, sweat secreted from sweat glands is an easily accessible source of biomarkers. In the following sections, we summarize various types of biosensors for sweat analysis, particularly focusing on the transistor-based biosensors.

\section{Transistor-based Biosensors for Highly Sensitive Sweat Analysis}

As the concentration of some biomarkers is much lower in sweat than in blood, ${ }^{29,30}$ highly sensitive biosensors are required for quantitative sweat analysis. Transistor-based biosensors are a promising type of sensing device for highly-sensitive sweat

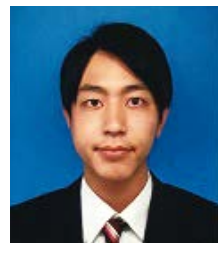

Ryota IzaWA received his bachelor's degree from Yamagata University. From 2019, he is a Master student of Graduate School of Organic Materials Science, Yamagata University. His research interest is development of a highly sensitive glucose sensor using enzymes and redox mediators to detect sweat glucose.

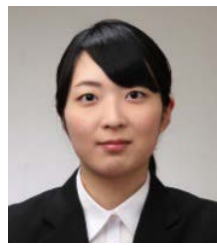

Shiori SASAKI received her bachelor's degree from Yamagata University. From 2019, she is a Master student of Graduate School of Organic Materials Science, Yamagata University. Her research interest is development of electrochemical immunosensor. is dever.

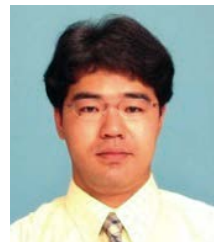

2013 to 2018. From 2019, he is Professor of Yamagata University. His research area includes biomolecular interaction analysis and biomolecular engineering for biosensors. 
analysis, as the biorecognition area is directly connected to an amplifier in its vicinity. ${ }^{31-35}$ Figure 1 shows typical structures for bottom-gate and electrolyte-gate type, transistor-based biosensors. The bottom-gate type has source and drain electrodes in contact with a semiconductor layer, with the bottom gate electrode indirectly contacting this layer via a dielectric layer. In a generic bottom-gate type of transistor device, the gate voltage applied between source and gate electrodes induces polarization of a dielectric layer, resulting in changes to the charge density at the interface between the semiconductor and dielectric layers. As a result, the sourcedrain current flowing in the semiconductor layer can be controlled by the applied gate voltage. In contrast, the gate electrode of a electrolyte-gate type of transistor is coupled to a semiconductor, through a sample solution acting as a dielectric layer. The gate voltage, applied between the source and gate electrodes, modulates the charge accumulation in an electric double layer at the interface between a sample solution and a semiconductor, resulting in changes to the charge density of the semiconductor.

In most transistor-based biosensors, bioreceptors are immobilized on a semiconductor - or a gate electrode-in preparation for exposure to a sample solution. When the bioreceptor layer is designed to generate change in the interfacial electrical potential, in accordance with the bioreceptor-analyte reaction, the gate voltage applied to the dielectric layer (bottom-gate type) or the sample solution/semiconductor interface (electrolyte-gate type) changes, depending on the reaction with analytes, with this change induces a change in the source-drain current. Based on this principle, a biorecognition reaction can be detected as either a change of threshold voltage $\left(V_{\mathrm{TH}}\right)$, which is the minimum gate voltage required to conduct a source-drain current, or a change in the source-drain current. In both types of device, the transistor input signal can be read out as an amplified sourcedrain current, depending on the mobility of the semiconductor, or the voltage generated by directing the source-drain current to other resistive elements, in series.

Direct exposure of a semiconductor to a sample solution sometimes induces unstable and unreproducible responsesparticularly an organic semiconductor, which can generally be sensitive to dissolved oxygen and humidity. To overcome this, an extended-gate structure has been established, as shown in Fig. 2(a). In the basic structure of this type of transistor-based biosensor, source and gate electrodes are connected to a reference electrode, and to a separately prepared, extended-gate electrode, whose surface is modified with a biorecognition layer, respectively. In this configuration, the transistor acts as an amplifier as well as a transducer for the potentiometric signal generated at the biorecognition layer (driving portion), and the extended-gate electrode is employed as the detection portion. The extended gate-type transistor is advantageous for stable and reproducible detection of analytes in a sample solution because the detection portion immersed in the sample solution can be completely isolated from the driving portion. ${ }^{36}$ In an extended (a)

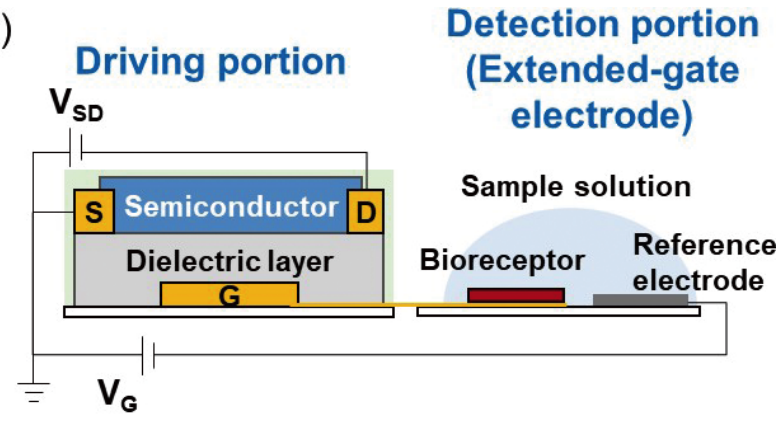

(b)

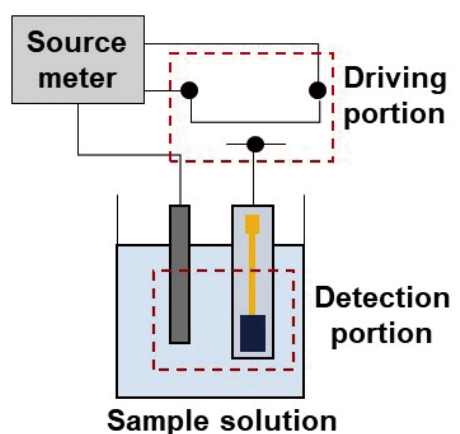

Fig. 2 (a) Structure of an extended-gate type transistor-based biosensor. (b) Setup of analyte sensing in a sample solution, using an extended-gate type transistor-based biosensor.

gate-type transistor, a gate voltage applied to a dielectric layer through a sample solution changes, depending on the bioreceptor reaction, which in turn induces a change in the source-drain current, as described above. Table 1 summarizes the representative transistor-based biosensors reported previously, and we selected only those used for artificial or human sweat measurements from the numerous transistor-based biosensor types available. These sensors have shown that they could detect analytes in the concentration range found in human sweat components. Our research group also has focused on developing extended-gate organic transistor-based biosensors for sweat analysis utilizing different types of bioreceptors: antibody, ${ }^{53-57}$ enzyme, ${ }^{58-66}$ and ionophore, ${ }^{67,68}$ because, as described below, the organic transistor can be mass-fabricated at low cost using advanced printed technology. The following typical fabrication process was used for our extended gate-type, organic, transistor-based biosensor. ${ }^{63}$ A silver nanoparticle ink in a hydrocarbon-based solution was printed as a gate electrode, using an inkjet printer, followed by sintering of the silver nanoparticles. A $150 \mathrm{~nm}$-thick parylene gate dielectric layer was then formed, by chemical vapor deposition. Source and drain electrodes were subsequently printed, using the same procedure and conditions as used for gate electrode fabrication. The bank layer, composed of

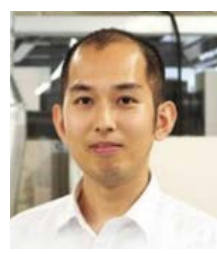

Hiroyuki Matsui received his $\mathrm{Ph}$. D. degree in 2011 from the University of Tokyo. He joined research group at National Institute of Advanced Industrial Science and Technology (AIST) (2011-2013), and the University of Tokyo as an Assistant Professor (2013 - 2016). Since 2016, he is Associate Professor of Yamagata University. His research area includes organic transistors, applied physics, experiments and simulations.

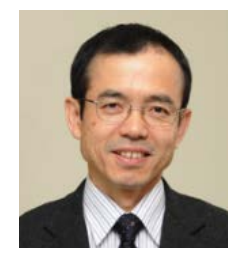

Shizuo TokITo received Doctor of Engineering and Master of Engineering degrees from Graduate School of Engineering and Sciences, Kyushu University, and become an Assistant Professor of Kyushu University. After that, he joined Toyota Central R\&D Labs Inc. as Senior Research Engineer and later then Science \& Technology Research Laboratories of Japan Broadcasting Corporation (NHK) as a Research Director. Currently he is a Director and Distinguished Research Professor at the Research Center for Organic Electronics (ROEL) within Yamagata University. $\mathrm{He}$ also published more 250 papers in the areas of organic light emitting diodes and organic thin film transistors (TFT), printed TFT circuits, biosensors as well as related flexible and printed electronics. 
Table 1 Summary of the transistor-based biosensors applied to artificial or human sweat analysis

\begin{tabular}{|c|c|c|c|c|}
\hline Transistor & Analyte & Sample solution & Detection range & Reference \\
\hline Commercial metal-oxide-semiconductor-based transistor & Cortisol & Artificial sweat & $10 \mathrm{fg} / \mathrm{mL}-10 \mathrm{ng} / \mathrm{mL}$ in PBS & 37 \\
\hline InGaZnO-based transistor & $\mathrm{pH}$ & Human sweat & $\mathrm{pH} 3-11$ & 38 \\
\hline $\mathrm{MoS}_{2}$-based transistor & $\mathrm{Na}^{+}$ & Human sweat & - & 39 \\
\hline $\mathrm{In}_{2} \mathrm{O}_{3}$-based transistor & Glucose & Artificial sweat & $1 \mu \mathrm{M}-1 \mathrm{mM}$ & 40 \\
\hline $\mathrm{In}_{2} \mathrm{O}_{3}$-based transistor & $\mathrm{pH}$ & Human sweat & $\mathrm{pH} 5-7.3$ & 41 \\
\hline \multirow[t]{4}{*}{$\mathrm{SiO}_{2} / \mathrm{Si}_{3} \mathrm{~N}_{4}$-based transistor } & $\mathrm{pH}$ & Human sweat & $\mathrm{pH} 4-7$ & 42 \\
\hline & $\mathrm{Na}^{+}$ & & $\mathrm{Na}^{+}: 1-100 \mathrm{~mm}$ & \\
\hline & $\mathrm{K}^{+}$ & & $\mathrm{K}^{+}: 1-50 \mathrm{mM}$ & \\
\hline & $\mathrm{Ca}^{2+}$ & & $\mathrm{Ca}^{2+}: 0.1-20 \mathrm{mM}$ & \\
\hline $\mathrm{SiO}_{2} / \mathrm{Si}_{3} \mathrm{~N}_{4}$-based transistor & $\mathrm{Na}^{+}$ & Human sweat & $10-120 \mathrm{mM}$ & 43 \\
\hline $\mathrm{SiO}_{2} / \mathrm{Si}_{3} \mathrm{~N}_{4}$-based transistor & $\mathrm{Na}^{+}$ & Human sweat & $10^{-5}-1 \mathrm{M}$ & 44 \\
\hline \multirow[t]{2}{*}{ AlGaN/GaN-based transistor } & $\mathrm{pH}$ & Human sweat & pH $3-7$ & 45 \\
\hline & $\mathrm{K}^{+}$ & & $\mathrm{K}^{+}: 10^{-6}-100 \times 10^{-3} \mathrm{M}$ & \\
\hline PEDOT:PSS-based organic electrochemical transistor & $\mathrm{pH}$ & Artificial sweat & pH $1-9$ & 46 \\
\hline PEDOT:PSS-based organic electrochemical transistor & $\mathrm{Ca}^{2+}, \mathrm{NH}_{4}^{+}$ & Human sweat & $\mathrm{Ca}^{2+}, \mathrm{NH}_{4}^{+}: 1-100 \mathrm{mM}$ & 47 \\
\hline PEDOT:PSS-based organic electrochemical transistor & Adrenaline & Human sweat & $10^{-6}-10^{-3} \mathrm{M}$ & 48 \\
\hline \multirow[t]{3}{*}{ PEDOT:PSS-based organic electrochemical transistor } & Adrenaline & Artificial sweat & Adrenaline: $10^{-4}-10^{-2} \mathrm{M}$ & 49 \\
\hline & Ascrobic acid & & Ascorbic acid: $3 \times 10^{-5}-5 \times 10^{-4} \mathrm{M}$ & \\
\hline & Dopamine & & Dopamine: $2 \times 10^{-6}-3 \times 10^{-5} \mathrm{M}$ & \\
\hline PEDOT:PSS-based organic electrochemical transistor & Cations & Human sweat & - & 50 \\
\hline PEDOT:PSS-based organic electrochemical transistor & Cortisol & Human sweat & $0.01-10 \mu \mathrm{M}$ & 51 \\
\hline Reduced graphene oxide-based transistor & Glucose & Artificial sweat & $10-400 \mu \mathrm{M}$ & 52 \\
\hline
\end{tabular}

fluoropolymer, was then printed, using a dispenser system. The source and drain electrodes were then modified with pentafluorobenzenethiol, to reduce contact resistance, and an organic semiconductor mixture was printed onto the area defined by the bank layer, using the dispenser system. Finally, an encapsulation layer of $1 \mathrm{wt} \%$ Teflon was printed by the dispenser system.

The extended-gate gold electrode was separately preparedby thermal evaporation on a substrate. For an oxidase-based biosensor, the carbon-graphite ink, including a redox compound of Prussian Blue (PB-carbon), was painted onto the active area through a stencil sheet. The lead line pattern was insulated by coating with a fluoropolymer, and a mixture solution composed of an oxidase and $0.1 \mathrm{wt} \%$ chitosan in phosphate buffer ( $\mathrm{pH} 6.8)$ was drop-cast onto the PB-carbon area. Figure 2(b) shows the setup for electrical characterization of the fabricated organic transistor-based biosensor, using a source meter to control the gate $\left(V_{\mathrm{G}}\right)$ and source-drain $\left(V_{\mathrm{SD}}\right)$ voltages. The bioreceptormodified extended-gate electrode and the $\mathrm{Ag} / \mathrm{AgCl}$ reference electrode were immersed in the sample solution, and their terminal ends were connected to the gate and source electrodes of the driving portion set outside of the sample solution, respectively.

Figure 3(a) shows one of our original extended-gate organic transistor-based enzymatic biosensors. The terminal ends of the extended-gate and reference electrodes were connected via an external resistor to induce a spontaneous reversible PB redox reaction driven by the difference in the formal redox potentials between these electrodes. This configuration produces a reversible and steady-state potentiometric signal, ${ }^{63}$ which is a critical and unresolved issue in conventional transistor-based enzymatic biosensors. The target analytes (D-glucose) are oxidized by the enzyme (glucose oxidase, GOx) generating hydrogen peroxide, followed by the reversible oxidation of redox mediator $\mathrm{PB}$ with the hydrogen peroxide. Figure 3(b) shows the typical time course of the reversible change in the source-drain current $\left(I_{\mathrm{SD}}\right)$ against repeated change of D-glucose concentration. Figure 3(c) depicts another type of organic transistor-based biosensor that can inform users of an overlimit in L-lactate concentration via a color change in an integrated electrophoretic display. ${ }^{65}$ This sensor was composed of lactate oxidase (LOx)/PB-modified extended-gate and $\mathrm{Ag} / \mathrm{AgCl}$ reference electrodes connected to the input line of a two-stage inverter circuit composed of organic transistors, and its output line was connected to an electrophoretic display. The two-stage organic inverter circuit exhibits an abrupt shift in output voltage depending on the potentiometric L-lactate sensor signal imposed on the constant input voltage of the inverter circuit, resulting in a distinct color change of the display connected to the output line of the inverter circuit (Fig. 3(d)). The L-lactate concentration limit was successfully tuned by changing the input voltage of the inverter circuit. This new type of biosensor is beneficial for users who do not have sufficient knowledge about the detected biomarkers because the threshold value of the sensor can arbitrarily be tuned by professionals, such as medical doctors or sports trainers, and the sensing result can be output as a simple signature.

In addition to these transistor-based biosensors, we included a recently developed electrochemical transistor that uses organic conducting polymers - such as poly(3,4-ethylenedioxythiophene): poly(styrenesulfonate) (PEDOT:PSS)—as a semiconductor layer in our summary shown in Table $1^{46-51}$ In this biosensor, with generally electrolyte-gate configuration, gate voltage against a gate electrode is applied to a conducting polymerbased semiconductor layer, through a sample solution, in order to control the doping level of the conducting polymer. A bioreceptor immobilized on the conducting polymer can induce change in the interfacial potential of the electric double layer through a biorecognition reaction. This results in the gate voltage applied to the conducting polymer changing, and is followed by changes to the source-drain current flowing in the conducting polymer. As the structure of the electrochemical transistor is quite simple and very flexible, and as most of its construction materials are liquid-based and printable, electrochemical transistor-based biosensors are expected to be suitable for application to low-cost, wearable-type, sweat sensors. 

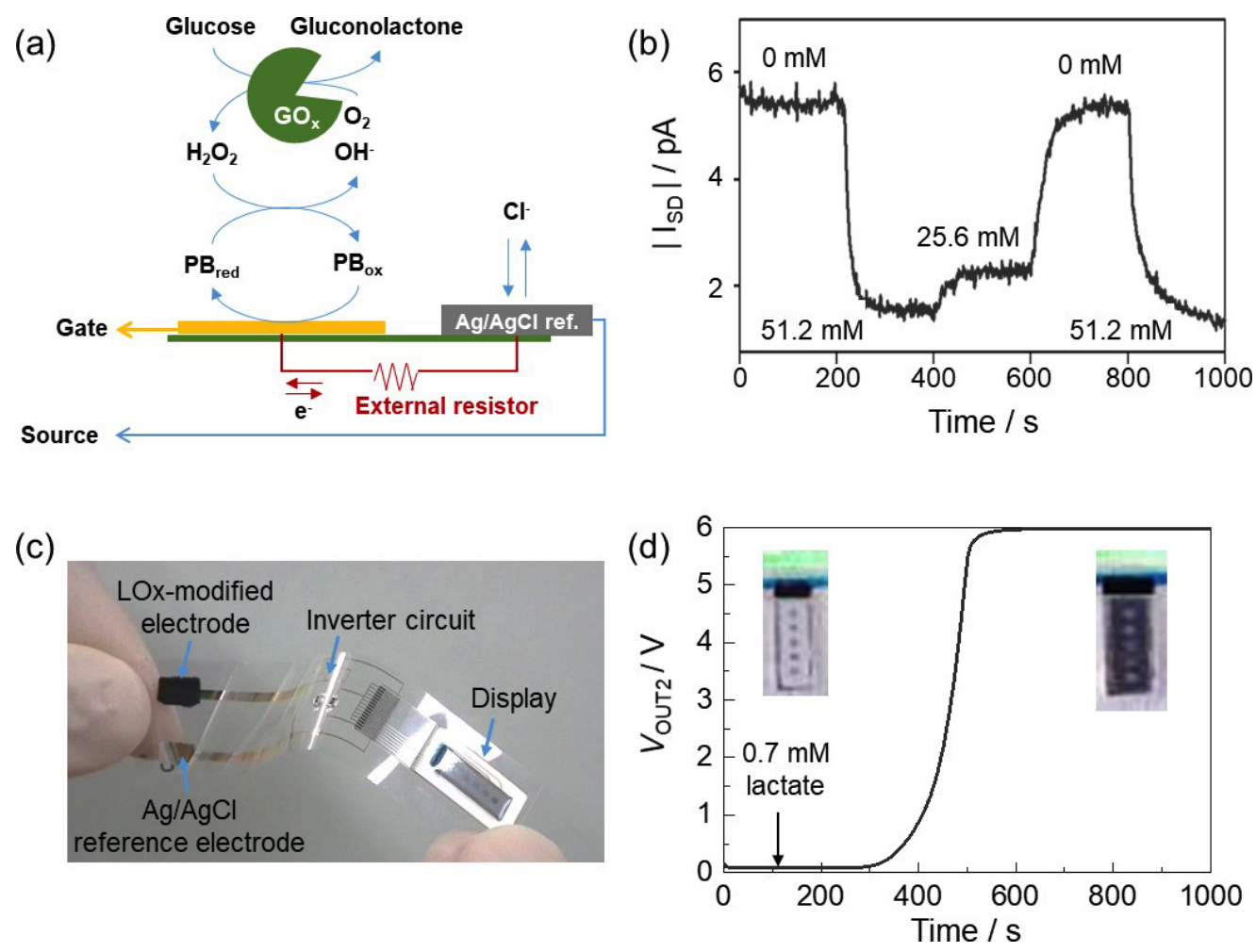

Fig. 3 (a) Principle of reversible response of the extended-gate organic transistor-based glucose sensor. (b) Change in $I_{\mathrm{DS}}$ of the sensor with time for repeated changes in D-glucose concentration in the measurement solution. (c) Photograph of the printed organic inverter-based biosensor prototype device with the display unit. (d) Time dependence of the output voltage $V_{\text {OUT2 }}$ of the device vs. L-lactate concentration. The concentration limit for L-lactate was set to $0.7 \mathrm{mM}$. The arrows represent the times of L-lactate injection.

While most conventional, transistor-based biosensors offer enough sensitivity and selectivity for sweat components, as summarized in Table 1, issues remain in terms of how to manage human health from sweat components, and how to collect sweat from a human body. The next section describes recent approaches to these issues.

\section{Sweat Biomarkers and Their Collection/ Detection Techniques}

Sweat has a similar composition to blood, and contains various possible biomarkers..$^{29,30}$ Table 2 summarizes the sweat biomarkers that have been studied. As the research on sweat biomarkers is still in progress, there are few reports of medical evidence and the concentration range to be quantified. Although some diseases can be diagnosed by measuring only one biomarker (such as glucose for diabetes, ${ }^{70}$ lactate or $\mathrm{NH}_{4}{ }^{+}$for fatigue due to anaerobic exercise, ${ }^{69,71-73}$ and $\mathrm{Cl}^{-}$for cystic fibrosis), ${ }^{74}$ recent omics analyses have revealed that most diseases should be carefully diagnosed by simultaneously measuring the change of multiple biomarkers in sweat. ${ }^{77,81-84}$ Hence, basic operational principles of sensors for sweat biomarkers should be based on highly-selective biorecognition reaction with reference to the conventional enzyme-based blood glucose sensors that utilize enzyme-modified Clark-type oxygen sensor electrodes. ${ }^{85}$ Integration of multiple biosensing elements into one chip enables the fabrication of biosensor arrays in a portable form. Gao et al. ${ }^{69}$ successfully produced a totally integrated wearable multi-biosensor to monitor lactate, glucose, and electrolytes simultaneously during bicycle exercise. "Totally integrated" means that the device is composed of not only a sensing element but also a signal conversion circuit, a wireless signal transmission module, and a battery. Such devices adopt both amperometric and potentiometric measurement systems - for lactate and glucose detection and for electrolyte detection, respectively. Since then, development of various types of totally integrated wearable sweat sensors have progressed to take the form of tattoo films, ${ }^{86-90}$ wrist bands, ${ }^{91-93}$ eye glasses, ${ }^{94}$ head bands, ${ }^{95}$ underwear, ${ }^{96-98}$ and socks. ${ }^{99}$ Although these sensors can detect analytes in sweat when the sensing elements are exposed to sweat, the detected sweat components are left in the same area and their concentration might increase as more sweat is secreted. This situation is unsuitable for real time monitoring of sweat components. One of the strategies for the continuous sampling and detection of sweat components is integration of these biosensors into on-skin microfluidic systems. ${ }^{80,87,100-105}$ In such applications, the microfluidic device is directly placed on the human skin, so that its inlet is in close contact with skin containing sweat glands (approximate eccrine sweat gland density: several hundred $\left.\mathrm{cm}^{-2}\right){ }^{29}$ In this configuration, sweat is passively introduced into the microchannel-in a typical perspiration rate range of a few $\mathrm{nL} \min ^{-1}$ gland ${ }^{-1}$ - by using the pressure generated in the sweat gland $\left(70 \mathrm{kN} \mathrm{m}^{-2}\right){ }^{29}$

Another issue is the induction of perspiration. In the case of a sweat sensor for daily healthcare application, a sufficient amount of sweat should be sampled anytime and anywhere. Although passive sweat collection methods are easy as described above, ${ }^{106}$ it takes a long time to sample a sufficient amount of 
Table 2 Summary of sweat biomarkers and their sampling/detection methods (the terms "amperometric electrode" and "potentiometric electrode" in the detection methods section mean that these sensor electrodes are not transistor-based biosensors)

\begin{tabular}{|c|c|c|c|}
\hline Disease & $\begin{array}{l}\text { Biomarkers for medical/ } \\
\text { healthcare applications }\end{array}$ & Sweat sampling/detection method & Reference \\
\hline Fatigue (unaerobic exercise) & Lactate & Bicycle exercise/amperometric enzyme-based sensor electrode & 69 \\
\hline Diabetes & Glucose & Warm condition/amperometric enzyme-based sensor electrode & 70 \\
\hline $\begin{array}{l}\text { Fatigue (unaerobic exercise), } \\
\text { Cirrhotic }\end{array}$ & $\mathrm{NH}_{4}^{+}$ & $\begin{array}{l}\text { Hot bath or exercise and direct collection/potentiometric } \\
\text { ion-selective electrode, bicycle exercise/potentiometric } \\
\text { ion-selective electrode, iontophoresis of pilocarpine and gauze } \\
\text { collection/colorimetric enzyme assay }\end{array}$ & $71,72,73$ \\
\hline Cystic fibrosis & $\mathrm{Cl}^{-}$ & $\begin{array}{l}\text { Iontophoresis of pilocarpine/potentiometric ion-selective } \\
\text { electrode }\end{array}$ & 74 \\
\hline $\begin{array}{l}\text { Heat stroke, Hypokalemia, } \\
\text { Muscle cramps, Dehydration }\end{array}$ & $\mathrm{Na}^{+}, \mathrm{K}^{+}$ & Bicycle exercise/potentiometric ion-selective electrode & 69,75 \\
\hline Atopic dermatitis & $\begin{array}{l}\text { Dermcidin } \\
\text { Amino acids }\end{array}$ & $\begin{array}{l}\text { Bicycle exercise and direct sampling/ELISA, warm condition } \\
\text { and direct sampling/GC/MS, cationic chromatography }\end{array}$ & 76,77 \\
\hline Lung cancer & $\begin{array}{l}\text { Monogluceride, muconic acid, } \\
\text { suberic acid, tetrahexose, } \\
\text { nonanedioic acid, urocanic acid }\end{array}$ & Iontophoresis of pilocarpine and direct sampling/LC-MS/MS & 78 \\
\hline Mental stress & $\begin{array}{l}\text { Cortisol } \\
\operatorname{IgA}\end{array}$ & $\begin{array}{l}\text { Running exercise/PEDOT:PSS-based organic electrochemical } \\
\text { transistor, bicycle exercise and sweat patch collection/ } \\
\text { amperometric immunosensor }\end{array}$ & 51,79 \\
\hline Kidney disorder & Creatinine, urea & Warm bath or shower/colorimetric enzyme assay & 80 \\
\hline Psoriasis & $\begin{array}{l}\text { Choline, glutamic acid, } \\
\text { phenylalaine, lactic acid, } \\
\text { urocanic acid, citruline }\end{array}$ & Hydrogel patch/mass spectrometry & 81 \\
\hline Active tuberculosis & Proteins & Iontophoresis of pilocarpine and direct sampling/LC-MS/MS & 82 \\
\hline Schizophrenia & Proteins & Iontophoresis of pilocarpine and direct sampling/LC-MS/MS & 83 \\
\hline Major depressive disorder & $\begin{array}{l}\text { Cytokines, neuropeptide } \mathrm{Y} \text {, } \\
\text { substance } \mathrm{P} \text {, calcitonin-gene- } \\
\text { related peptide, vasoactive } \\
\text { intestinal peptide }\end{array}$ & $\begin{array}{l}\text { Sweat patch collection for } 24 \mathrm{~h} / \text { recycling immunoaffinity } \\
\text { chromatography }\end{array}$ & 84 \\
\hline
\end{tabular}

sweat for biosensors. Therefore, most researchers sampled sweat from the human skin surface during strenuous exercise or in a specially prepared warm environment, as summarized in Table 2. Gao et al. integrated an iontophoretic drug delivery system into a wearable sweat biosensor to actively induce perspiration on demand using a cholinergic agonist, such as pilocarpine. ${ }^{74}$ Iontophoresis is a technique that is widely used to deliver a chemical compound into the skin with the aid of a direct current. A pair of iontophoresis electrodes covered by hydrogels containing a cholinergic agonist are fabricated near the amperometric or potentiometric electrochemical biosensing electrodes. The device is placed on the human skin so that the hydrogel on the iontophoretic electrodes and the biosensing electrodes are in contact with the skin, and then the electrochemical signal is monitored using a wireless integrated flexible printed circuit board, after iontophoretically delivering pilocarpine. The researchers successfully demonstrated periodic monitoring of sweat glucose ${ }^{74}$ and drugs ${ }^{107}$ using this device. However, the applied direct current sometimes makes the users uncomfortable. Besides, periodic drug administration is not recommended for healthy individuals and the elderly.

Tsuda et al. ${ }^{108,109}$ proposed an innovative straightforward and simple periodic sweat sampling method. Human skin was exposed to $1 \mathrm{vol} \%$ aqueous ethanol to extract the sweat component, as shown in Fig. 4. They emphasized that the addition of ethanol into water induces less surface tension of the solution to the skin, thereby allowing the solution to penetrate the sweat gland effectively. This sweat component sampling method has also been used for recent proteomic and metabolomic analyses. ${ }^{110-112}$ Tsunoda et al. ${ }^{113}$ suggested a clear correlation between extracted sweat and plasma component levels.

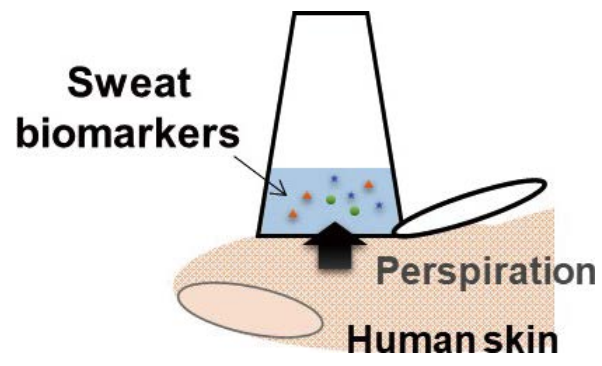

Fig. 4 Schematic view of sweat extraction method.

However, in this method, the secreted sweat analyte is further diluted in the extraction solution even though the concentration of analytes in the original sweat is much lower than that in the blood. Therefore, the extracted sweat components were quantified using a separately prepared highly sensitive analytical system, such as liquid chromatography and mass spectrometry. ${ }^{108-113}$ These analytical systems are not compatible with daily healthcare applications due to its size, cost, and requirement of high technical skill. For daily healthcare, this sweat extraction technique should be combined with portable and highly sensitive biosensors for on-site detection of the extracted low level of sweat components. Additionally, the aqueous ethanol should be replaced with another solution that is compatible with bioreceptors.

Previous reports have suggested that a saline is a suitable solution for continuous sweat extraction, because a saline with physiological osmotic pressure suppresses mechanical swelling 
of the human skin, thereby keeping the sweat gland open in the solution. ${ }^{14-116}$ Based on this result, we performed a phosphatebuffered saline (PBS)-based sweat extraction using the method proposed by Tsuda. ${ }^{108,109}$ After washing the forefingers of the subjects with running $1 \%(\mathrm{v} / \mathrm{v})$ ethanol-water for $15 \mathrm{~s}$, a $0.6-\mathrm{mL}$ microcentrifuge tube containing $30-\mu \mathrm{L}$ of PBS was put on the washed fingers as PBS was exposed to the skin surface for 10 min (L-lactate, D-glucose, and $\mathrm{NH}_{4}^{+}$detection) or $30 \mathrm{~min}$ (IgG detection) at room temperature. The concentrations of the extracted biomarkers were then quantified using commercially available assay kits for D-glucose (LabAssay ${ }^{\mathrm{TM}}$ Glucose, FUJIFILM Wako Pure Chemicals), $\mathrm{NH}_{4}{ }^{+}$(LabAssay ${ }^{\mathrm{TM}}$ Ammonia, FUJIFILM Wako Pure Chemicals), IgG (Human IgG ELISA Quantification Set, Bethyl Laboratories, Inc.), and L-lactate sensor (Lactate Pro2, Arkray). Table 3 shows the concentrations of these biomarkers in the extracted human sweat. All the biomarkers were included in the extracted human sweat in the detectable concentration range of commercial bioassay kits. The concentration of each biomarker was as follows: L-lactate $1.96 \pm 0.88 \mathrm{mM} \quad(n=5)$, D-glucose $2.60 \pm 1.30 \mu \mathrm{M} \quad(n=4)$, $\mathrm{NH}_{4}{ }^{+} 0.15 \pm 0.07 \mathrm{mM}(n=6)$, and $\mathrm{IgG} 11.49 \pm 13.41 \mathrm{ng} / \mathrm{mL}$ $(n=3)$. These results suggest the possibility of combining this sweat extraction method with biosensors.

Based on these factors, we invented a new sweat extraction and detection device. ${ }^{66}$ The sensor was composed of an enzymebased L-lactate sensor and $\mathrm{Ag} / \mathrm{AgCl}$ reference electrodes, prepared in the same way as described in Fig. 3(a), and were fully covered with an agarose hydrogel including a sweatextraction solution of PBS (Fig. 5(a)). The sweat L-lactate can be continuously extracted from human skin in contact with the agarose hydrogel, followed by in-situ detection using the biosensors. The L-lactate sensor was composed of a carbon electrode containing Prussian Blue (PB) onto which LOx was immobilized using a chitosan polymer. Meanwhile, L-lactate was oxidized by LOx with the generation of hydrogen peroxide,

Table 3 Concentration of human sweat biomarkers extracted in PBS

Biomarker Concentration of biomarker in PBS extraction solution

\begin{tabular}{lc}
\hline L-Lactate & $1.96 \pm 0.88 \mathrm{mM}(n=5)$ \\
D-Glucose & $2.60 \pm 1.30 \mu \mathrm{M}(n=4)$ \\
$\mathrm{NH}_{4}{ }^{+}$ & $0.15 \pm 0.07 \mathrm{mM}(n=6)$ \\
$\mathrm{IgG}$ & $11.49 \pm 13.41 \mathrm{ng} / \mathrm{mL}(n=3)$ \\
\hline
\end{tabular}

followed by oxidation of redox mediator PB from di- to trivalent form with the hydrogen peroxide (Fig. 5(a)). As a result, the electric potential of the electrode positively changed according to the Nernstian equation. Concerning the operational principle of the transistor device, the change in $V_{\mathrm{TH}}$ is expected to be equal to the change in the electrical potential of the extended-gate electrode. Therefore, basic characterization of just the bioreceptor-modified extended-gate portion can be separately studied by means of potentiometric measurements. ${ }^{63}$ Figure 5(b) shows the potentiometric response of the LOx/PBmodified electrode when the ball of the forefinger was put on the agarose gel surface at $100 \mathrm{~s}$ for $30 \mathrm{~s}$. After $50 \mathrm{~s}$ of time lag for the diffusion of the extracted L-lactate in the gel, the potential difference started to increase, followed by an approaching steady state. Without LOx, no potentiometric response was observed when the forefinger touched the gel, thereby suggesting that the extracted sweat compounds (except for L-lactate) did not affect the sensor response. To the best of our knowledge, this is the first report of a non-invasive and straightforward sweat component extraction and detection method using a portable biosensor without any perspiration assistance, such as exercise, environmental temperature control, or a cholinergic agonist. We expect similar sweat sensors to appear and make further progress in the near future. ${ }^{117}$

\section{Advanced Printed Biosensor Systems Based on Flexible Hybrid Electronics (FHE)}

The low-cost mass production of biosensor systems is another challenge that, if addressed, can lead to the mass adoption of biosensors in daily healthcare. Printing technology has emerged as a low-cost, environmental-friendly mass-manufacturing technology for the fabrication of next-generation printed flexible electronics devices. There are a number of printing methods that can be applied to biosensor fabrication, such as inkjet printing, ${ }^{118-123}$ screen printing, ${ }^{8,124}$ flexographic printing, ${ }^{125,126}$ and gravure printing ${ }^{127-132}$ (Fig. 6(a)). The characteristics of these representative printing methods have been summarized in Table 4. ${ }^{133}$ These methods can be selected on-demand, depending on the type, size, ink/paste materials, and degree of biosensor integration, as they have different characteristics in terms of print resolution, print thickness, and printing speed. Inkjet printing, for example, is well known as a promising method for straightforward digital, on-demand patterning, in liquid-based biomaterials, without the use of a printing mask or (a)

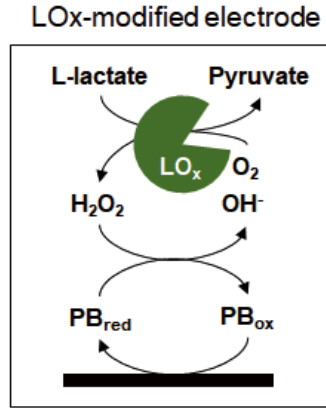

(b)

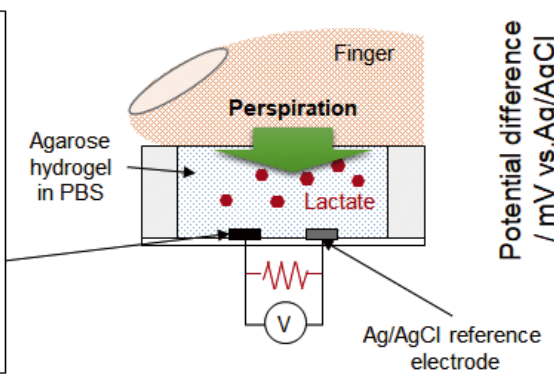

Fig. 5 (a) Structure of the human sweat L-lactate extraction and detection device. The left side figure represents the enzymatic reaction generated on the LOx-modified electrode. (b) Potentiometric response of the sensor electrodes when the ball of the forefinger comes in contact with the agarose gel surface at $100 \mathrm{~s}$. 
(a)

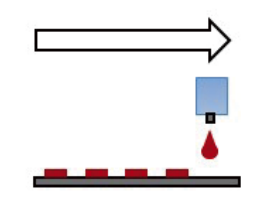

Inkjet printing

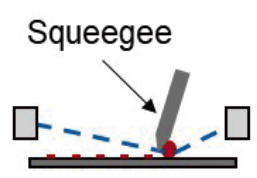

Screen printing

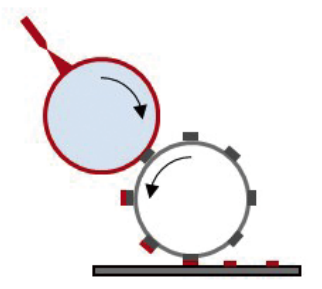

Flexographic printing

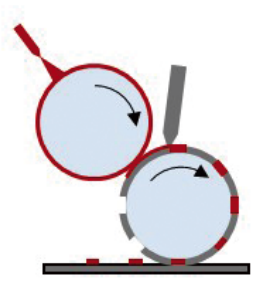

Gravure printing (b)

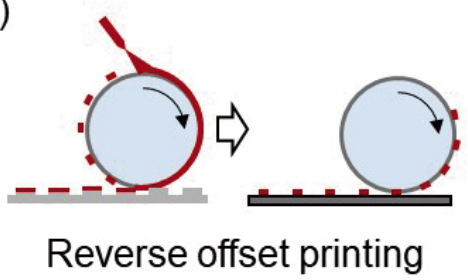

(c)

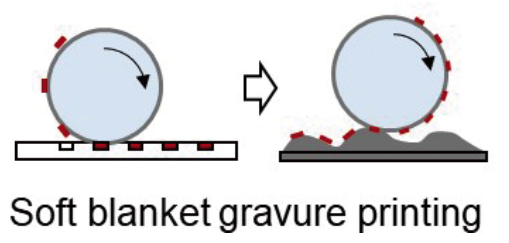

Fig. 6 Schematic of various types of printing techniques involving: (a) inkjet, screen, flexographic, and gravure printing; (b) reverse offset printing; (c) soft blanket gravure printing.

Table 4 Comparison of representative printing techniques

\begin{tabular}{lcccc}
\hline \multicolumn{1}{c}{ Parameter } & Inkjet & Screen & Flexographic & Gravure \\
\hline Print resolution $/ \mu \mathrm{m}$ & $15-100$ & $30-100$ & $30-80$ & $50-200$ \\
Print thickness $/ \mu \mathrm{m}$ & $0.01-0.5$ & $3-30$ & $0.17-8$ & $0.02-12$ \\
Printing speed/m min m $^{-1}$ & $0.02-5$ & $0.6-100$ & $5-180$ & $8-100$ \\
Required ink viscosity/Pa·s & $0.001-0.1$ & $0.5-5$ & $0.01-0.5$ & $0.01-1.1$ \\
Ink surface tension $/ \mathrm{mN} \mathrm{m}^{-1}$ & $15-25$ & $38-47$ & $13.9-23$ & $41-44$ \\
Remarks & Mask-less, digital & Simple, high speed, & High speed large area & High speed large area \\
& on-demand printing & large area printing & printing & printing \\
\hline
\end{tabular}

plate, although its spatial resolution is limited to the $15-100 \mu \mathrm{m}$ range. Screen printing is simply carried out in large areas by squeezing a liquid paste through a patterned mesh screen mask onto a substrate. Generally, the paste for screen printing is a mixture of a non-biocompatible binding agent and solvent, to provide suitable viscosity and volatility for thermal curing, and application of this technique to biomolecule patterning remains challenging. Both flexographic and gravure printing techniques use rotary cylinders whose surfaces have raised or engraved patterns, respectively, fabricated to hold the ink. In these printing techniques, ink can be transferred from the rotary cylinder onto a substrate at high speed, over a large area, and at low-cost, but there are few reports of their application to biosensor fabrication - and this is perhaps due to the need for custom-made rotary cylinders.

Recently, other printing techniques have emerged for advanced printed electronics. Reverse offset printing is a unique technique used to obtain high resolution fine patterns over a large area, at scales of $<5 \mu \mathrm{m}$ (Fig. $6(\mathrm{~b})$ ). ${ }^{134,135}$ There are three main steps in the reverse offset printing process: coating, patterning, and transfer. First, ink is coated onto a silicone-based blanket with a slit coater. Next, unnecessary areas are removed from the blanket with a glass printing plate, and then the ink on the blanket is transferred to the substrate. Reverse offset printing will be an attractive technique for obtaining high resolution biosensor arrays in the near future, although establishment of its printing process is still challenging.
Soft blanket gravure printing is another advanced printing technology (Fig. 6(c)). ${ }^{136}$ As this printing system uses a soft and thick blanket to transfer the ink, direct and on-demand printing of biosensing systems can be achieved on the three-dimensional curved surfaces of conventional wearable medical devicessuch as mouth guards, soft contact lenses, wound dressings, wristbands, and in the future, even human skin. ${ }^{137}$

In order to print biomolecules using these techniques, the printing ink composition has to be optimized for the selected printing method and biomaterials. ${ }^{125}$ For example, biomaterials require aqueous buffer solutions to maintain physiological activity in the ink. In addition, humectants, such as ethylene glycol and glycerol, are required to prevent ink from drying in the applicator nozzle, while stabilizers, such as trehalose, glucose, or sucrose, are needed to maintain biomaterial structure and activity. These additives need to be included in the ink, and its viscosity and surface tension need to be retained at levels appropriate to the selected printing method. Overall, it can be seen that, in the printed electronics field, the sophisticated tuning of ink composition requires ongoing research.

To realize simple and portable/wearable sensors for IoT applications, the total integration of the sensor system for the sensor electrode as well as the surrounding circuits for amplification, A/D conversion, and wireless transmission of the detected signals on a single thin film substrate is ultimately necessary. In particular, the advanced printing technologies described above will enable the low-cost mass production of the 


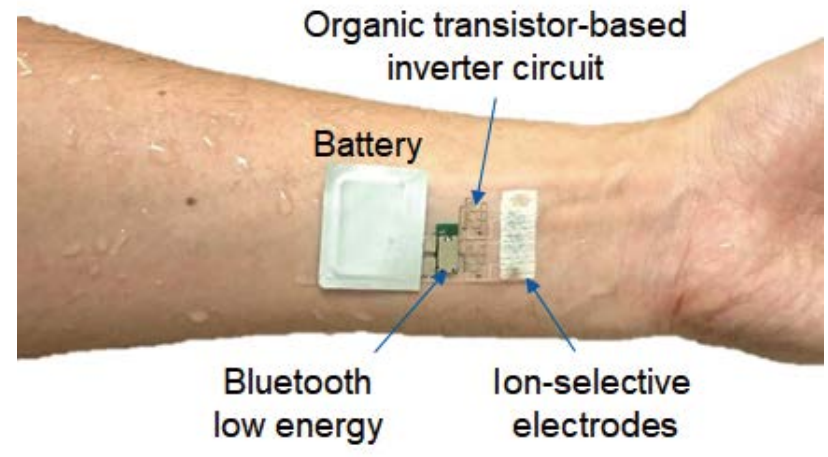

Fig. 7 Photograph of a mockup of a BLE-type FHE wireless biosensor device fabricated on thin plastic film.

integrated sensors. Recently, a new approach to realize a totally integrated printed sensor system has been adopted, called flexible hybrid electronics (FHE), where LSI die-based silicon circuit technology is utilized together with printing technology on a thin plastic film substrate. In FHE, sensors, interconnects, and antennas are first printed on a plastic film, and Si-LSI die and resistors are mounted onto the same film substrate. Meanwhile, near-field communication or Bluetooth low energy (BLE) protocols are used for wireless communication. Flexible hybrid electronics has become the default platform even in the field of wearable biosensor development. ${ }^{138,139}$ The photograph in Fig. 7 shows a mockup of an FHE-based, wearable sweat biosensor fabricated for this review, to show readers. The circuit was composed of an organic transistor-based inverter connected to a potentiometric extended-gate sensor electrode to amplify the signal. ${ }^{67}$ The active area of the extended-gate electrode was covered with potassium ion-selective membranes, to prepare the potentiometric potassium ion sensors. For the reference electrode, an $\mathrm{Ag} / \mathrm{AgCl}$ paste was painted. The output line of the inverter circuit was connected to a BLE module, to transmit the amplified signal to an external smartphone or tablet PC. The necessary operational power was supplied from a commercially available, thin Li-battery. Although flexibility, thinness, and cost of FHE devices are other issues, this strategy has proven quite useful in enabling the practical use of reliable, portable, and wearable biosensors. Ultimately, future progress in printed organic electronics will replace the Si-LSI die with printed integrated circuits based on organic transistor devices, allowing for totally printable and organic integrated multi-biosensor devices that can potentially be mass fabricated at low cost.

\section{Conclusions}

This review describes recent rapid progress in the development of transistor-based biosensors for non-invasive sweat analysis, and the details of our approach based on printed electronics. Printed electronics is a promising future technology for low-cost mass fabrication of portable/wearable multi-biosensing systems that will enable reliable sweat-based healthcare. Besides, the integration of wireless communication systems into biosensors with flexible hybrid electronics technology facilitates the connection of personal human data to the Internet, thereby enabling the provision of personal healthcare services in the future.

On the other hand, not only the development of printed electronics, but also the continuous sampling method for slightly excreted fresh human sweat is still challenging in this field. Although we think that our hydrogel-based sweat sensor is one of the potential solutions for the effective and easy periodic sampling of human sweat in a non-invasive manner, various interferences such as perspiration rate, skin surface temperature, and contamination with transepidermaly diffused compounds should be considered for reliable sweat analysis. Hence, these issues are solved with a simple device configuration and biocompatible manner for the reproducible mass manufacturing of integrated biosensors as well as the quantitative and safe analysis of sweat components.

\section{Acknowledgements}

We would like to acknowledge each of our laboratory members and our colleagues for their productive discussions and contributions to these experiments. This review involves the results of several projects that are financially supported by the Center of Innovation Program (COI) of the Japan Science and Technology Agency, JST, Leading Initiative for Excellent Young Researchers (LEADER), a Grant-in-Aid for Scientific Research C (18K04910) from the Ministry of Education, Culture, Sports, Science and Technology, Japan, and the Foundation for Technology Promotion of Electronic Circuit Board.

\section{Ethical Approval}

All procedures performed in studies involving human participants were in accordance with the standards of the Ethics Committee of the Faculty of Medicine, Yamagata University. All the experimental protocols involving human participants were approved by the Ethics Committee of the Faculty of Medicine, Yamagata University (Approval No. 30-7). Before carrying out the experiments, the purpose of this study was explained to subjects who signed the university-approved informed consent form.

\section{References}

1. C. Wang, K. Xia, H. Wang, X. Liang, Z. Yin, and Y. Zhang, Adv. Mater., 2019, 31, 1801072.

2. Y. Liu, M. Pharr, and G. A. Salvatore, ACS Nano, 2017, 11, 9614.

3. F. Yi, Z. Zhang, Z. Kang, Q. Liao, and Y. Zhang, $A d v$. Funct. Mater, 2019, 29, 1808849.

4. M. U. Ahmed, I. Saaem, P. C. Wu, and A. S. Brown, Crit. Rev. Biotechnol., 2014, 34, 180.

5. C. Dincer, R. Bruch, A. King, P. S. Dittrich, and G. A. Urban, Trends Biotechnol., 2017, 35, 728.

6. L. Syedmoradi, M. Daneshpour, M. Alvandipour, F. A. Gomez, H. Hajghassem, and K. Omidfar, Biosens. Bioelectron., 2017, 87, 373.

7. A. Tricoli, N. Nasiri, and S. De, Adv. Funct. Mater, 2017, 27, 1605271

8. J. Kim, R. Kumar, A. J. Bandodkar, and J. Wang, $A d v$. Electron. Mater., 2017, 3, 1600260.

9. A. J. Bandodkar, I. Jeerapan, and J. Wang, ACS Sens., 2016, $1,464$.

10. K. Guk, G. Han, J. Lim, K. Jeong, T. Kang, E. Lim, and J. Jung, Nanomaterials, 2019, 9, 813.

11. W. Gao, H. Ota, D. Kiriya, K. Takei, and A. Javey, Acc. 
Chem. Res., 2019, 52, 523.

12. Y. Yang and W. Gao, Chem. Soc. Rev., 2019, 48, 1465.

13. A. K. Yetisen, J. L. Martinez-Hurtado, B. Ünal, A. Khademhosseini, and H. Butt, Adv. Mater, 2018, 30, 1706910.

14. J. Heikenfeld, A. Jajack, J. Rogers, P. Gutruf, L. Tian, T. Pan, R. Li, M. Khine, J. Kim, J. Wang, and J. Kim, Lab Chip, 2018, 18, 217.

15. K. Kalantar-zadeh, N. Ha, J. Z. Ou, and K. J. Berean, ACS Sens., 2017, 2, 468.

16. K. Scholten and E. Meng, Int. J. Pharm., 2018, 544, 319.

17. F. Wu, P. Yu, and L. Mao, Curr. Opin. Electrochem., 2017, $5,152$.

18. J. J. Hong, H. Jeong, K. W. Cho, N. Lu, and D. H. Kim, Adv. Funct. Mater., 2019, 29, 1808247.

19. M. Z. Bidin, A. M. Shah, J. Stanslas, and C. L. T. Seong, Clin. Chim. Acta, 2019, 495, 239.

20. J. Heikenfeld, A. Jajack, B. Feldman, S. W. Granger, S. Gaitonde, G. Begtrup, and B. A. Katchman, Nat. Biotechnol., 2019, 37, 407.

21. J. Kim, A. S. Campbell, B. Esteban-Fernández de Ávila, and J. Wang, Nat. Biotechnol., 2019, 37, 389.

22. C. G. Engeland, J. A. Bosch, and N. Rohleder, Curr. Opin. Behav. Sci., 2019, 28, 58.

23. E. F. Sato, T. Choudhury, T. Nishikawa, and M. Inoue, J. Clin. Biochem. Nutr., 2008, $42,8$.

24. X. Wang, K. E. Kaczor-Urbanowicz, and D. T. W. Wong, Med. Oncol., 2017, 34, 7.

25. K. E. Kaczor-Urbanowicz, C. M. Carreras-Presas, T. Kaczor, M. Tu, F. Wei, F. Garcia-Godoy, and D. T. W. Wong, J. Cell. Mol. Med., 2017, 21, 640.

26. S. Mishra, D. Saadat, O. Kwon, Y. Lee, W. S. Choi, J. H. Kim, and W. H. Yeo, Biosens. Bioelectron., 2016, 81, 181.

27. N. M. Farandos, A. K. Yetisen, M. J. Monteiro, C. R. Lowe, and S. H. Yun, Adv. Healthcare Mater., 2015, 4, 792.

28. Z. Mutlu, S. S. Es-haghi, and M. Cakmak, Adv. Healthcare Mater, 2019, 8, 1801390.

29. Z. Sonner, E. Wilder, J. Heikenfeld, G. Kasting, F. Beyette, D. Swaile, F. Sherman, J. Joyce, J. Hagen, N. KelleyLoughnane, and R. Naik, Biomicrofluidics, 2015, 9, 031301.

30. M. Bariya, H. Y. Y. Nyein, and A. Javey, Nat. Electron., 2018, $1,160$.

31. M. Kaisti, Biosens. Bioelectron., 2017, 98, 437.

32. H. Li, W. Shi, J. Song, H. J. Jang, J. Dailey, J. Yu, and H. E. Katz, Chem. Rev., 2019, 119, 3.

33. J. Choi, T. W. Seong, M. Jeun, and K. H. Lee, $A d v$. Healthcare Mater., 2017, 6, 1700796.

34. C. Liao, M. Zhang, M. Y. Yao, T. Hua, L. Li, and F. Yan, Adv. Mater., 2015, 27, 7493.

35. X. Strakosas, M. Bongo, and R. M. Owens, J. Appl. Polym. Sci., 2015, 132, 41735.

36. D. Wang, V. Noël, and B. Piro, Electronics, 2016, 5, 9.

37. H. J. Jang, T. Lee, J. Song, L. Russell, H. Li, J. Dailey, P. C. Searson, and H. E. Katz, ACS Appl. Mater. Interfaces, 2018, 10, 16233.

38. S. Nakata, T. Arie, S. Akita, and K. Takei, ACS Sens., 2017, 2, 443.

39. P. Li, D. Zhang, and Z. Wu, Sens. Actuators, A, 2019, 286, 51.

40. Q. Liu, Y. Liu, F. Wu, X. Cao, Z. Li, M. Alharbi, A. N. Abbas, M. R. Amer, and C. Zhou, ACS Nano, 2018, 12, 1170 .

41. G. Scheiblin, R. Coppard, R. M. Owens, P. Mailley, and G. G. Malliaras, Adv. Mater. Technol., 2017, 2, 1600141.

42. J. Zhang, M. Rupakula, F. Bellando, E. Garcia Cordero,
J. Longo, F. Wildhaber, G. Herment, H. Guérin, and A. M. Ionescu, ACS Sens., 2019, 4, 2039.

43. A. Cazalé, W. Sant, F. Ginot, J. -C. Launay, G. Savourey, F. Revol-Cavalier, J. M. Lagarde, D. Heinry, J. Launay, and P. Temple-Boyer, Sens. Actuators, B, 2016, 225, 1.

44. A. Cazalé, W. Sant, J. Launay, F. Ginot, and P. TempleBoyer, Sens. Actuators, B, 2017, 177, 515.

45. X. Liu, L. Zhao, B. Miao, Z. Gu, J. Wang, H. Peng, J. Li, W. Sun, and J. Li, Electroanalysis, 2019, 31, 1.

46. F. Mariani, I. Gualandi, M. Tessarolo, B. Fraboni, and E. Scavetta, ACS Appl. Mater. Interfaces, 2018, 10, 22474.

47. S. T. Keene, D. Fogarty, R. Cooke, C. D. Casadevall, A. Salleo, and O. Parlak, Adv. Healthcare Mater, 2019, 1901321.

48. N. Coppedè, G. Tarabella, M. Villani, D. Calestani, S. Iannotta, and A. Zappettini, J. Mater. Chem. B, 2014, 2, 5620 .

49. I. Gualandi, M. Marzocchi, A. Achilli, D. Cavedale, A. Bonfiglio, and B. Fraboni, Sci. Rep., 2016, 6, 33637.

50. Y. Kim, T. Lim, C. H. Kim, C. S. Yeo, K. Seo, S. M. Kim, J. Kim, S. Y. Park, S. Ju, and M. H. Yoon, NPG Asia Mater, 2018, 10, 1086.

51. O. Parlak, S. T. Keene, A. Marais, V. F. Curto, and A. Salleo, Sci. Adv., 2018, 4, eaar2904.

52. M. Ma, Y. Zhou, J. Ii, Z. Ge, H. He, T. Tao, Z. Cai, X. Wang, G. Chang, and Y. He, Analyst, 2020, 145, 887.

53. T. Minamiki, T. Minami, Y. Sasaki, S. Wakida, R. Kurita, O. Niwa, and S. Tokito, Sensors, 2016, 16, 2033.

54. T. Minamiki, T. Minami, Y, Sasaki, R. Kurita, O. Niwa, S. Wakida, and S. Tokito, Anal. Sci., 2015, 31, 725.

55. T. Minamiki, T. Minami, R. Kurita, O. Niwa, S. Wakida, K. Fukuda, D. Kumaki, and S. Tokito, Materials, 2014, 7, 6843.

56. T. Minamiki, T. Minami, R. Kurita, O. Niwa, S. Wakida, K. Fukuda, D. Kumaiki, and S. Tokito, Appl. Phys. Lett., 2014, 104, 243703.

57. K. Fukuda, T. Minamiki, T. Minami, M. Watanabe, T. Fukuda, D. Kumaki, and S. Tokito, Adv. Electron. Mater., 2015, $1,1400052$.

58. T. Minami, Y. Sasaki, T. Minamiki, S. Wakida, R. Kurita, O. Niwa, and S. Tokito, Biosens. Bioelectron., 2016, 81,87 .

59. T. Minami, T. Sato, T. Minamiki, and S. Tokito, Anal. Sci., 2015, 31, 721.

60. T. Minami, T. Sato, T. Minamiki, K. Fukuda, D. Kumaki, and S. Tokito, Biosens. Bioelectron., 2015, 74, 45.

61. R. Shiwaku, H. Matsui, K. Nagamine, M. Uematsu, T. Mano, Y. Maruyama, A. Nomura, K. Tsuchiya, K. Hayasaka, Y. Takeda, T. Fukuda, D. Kumaki, and S. Tokito, Sci. Rep., 2018, 8, 6368.

62. H. Furusawa, Y. Ichimura, K. Nagamine, R. Shiwaku, H. Matsui, and S. Tokito, Technologies, 2018, 6, 77.

63. T. Mano, K. Nagamine, Y. Ichimura, R. Shiwaku, H. Furusawa, H. Matsui, D. Kumaki, and S. Tokito, ChemElectroChem, 2018, 24, 3881.

64. K. Sasaki, H. Furusawa, K. Nagamine, and S. Tokito, Chem. Lett., 2018, 47, 1412.

65. K. Nagamine, T. Mano, R. Shiwaku, H. Furusawa, H. Matsui, D. Kumaki, and S. Tokito, Sens. Mater., 2019, 31, 1205.

66. K. Nagamine, T. Mano, A. Nomura, Y. Ichimura, R. Izawa, H. Furusawa, H. Matsui, D. Kumaki, and S. Tokito, Sci. Rep., 2019, 9, 10102.

67. R. Shiwaku, H. Matsui, K. Nagamine, M. Uematsu, T. Mano, Y. Maruyama, A. Nomura, K. Tsuchiya, K. Hayasaka, Y. Takeda, T. Fukuda, D. Kumaki, and S. Tokito, 
Sci. Rep., 2018, 8, 3922.

68. K. Nagamine, H. Yoshimine, K. Tsuchiya, A. Nomura, and S. Tokito, Chemical Sensors, 2018, 34, 2.

69. W. Gao, S. Emaminejad, H. Y. Y. Nyein, S. Challa, K. Chen, A. Peck, H. M. Fahad, H. Ota, H. Shiraki, D. Kiriya, D. H. Lien, G. A. Brooks, R. W. Davis, and A. Javey, Nature, 2016, 529, 509.

70. H. Lee, T. K. Choi, Y. B. Lee, H. R. Cho, R. Ghaffari, L. Wang, H. J. Choi, T. D. Chung, N. Lu, T. Hyeon, S. H. Choi, and D. H. Kim, Nat. Nanotech., 2016, 11, 566.

71. K. Mitsubayashi, M. Suzuki, E. Tamiya, and I. Karube, Anal. Chim. Acta, 1994, 289, 27.

72. D. Czarnowski, J. Górski, J. Jóźwiuk, and A. BorońKaczmarska, Eur. J. Appl. Physiol., 1992, 65, 135.

73. T. Guinovart, A. J. Bandodkar, J. R. Windmiller, F. J. Andrade, and J. Wang, Analyst, 2013, 138, 7031.

74. S. Emaminejad, W. Gao, E. Wu, Z. A. Davies, H. Y. Y. Nyein, S. Challa, S. P. Ryan, H. M. Fahad, K. Chen, Z. Shahpar, S. Talebi, C. Milla, A. Javey, and R. W. Davis, Proc. Natl. Acad. Sci. U.S.A., 2017, 114, 4625.

75. Y. Epstein and W. O. Roberts, Scand. J. Med. Sci. Sports, 2011, 21, 742 .

76. S. Rieg, H. Steffen, S. Seeber, A. Humeny, H. Kalbacher, K. Dietz, C. Garbe, and B. Schittek, J. Immunol., 2005, 174,8003 .

77. H. Mark and C. R. Harding, Int. J. Cosmetic Sci., 2013, 35, 163.

78. M. del Mar Delgado-Povedano, M. Calderón-Santiago, F. Priego-Capote, B. Jurado-Gámez, and M. D. L. de Castro, Metabolomics, 2016, 12, 166.

79. A. Crew, C. Alford, D. C. C. Cowell, and J. P. Hart, Electrochim. Acta, 2007, 52, 5232.

80. Y. Zhang, H. Guo, S. B. Kim, Y. Wu, D. Ostojich, S. H. Park, X. Wang, Z. Weng, R. Li, A. J. Bandodkar, R. Ghaffai, and J. A. Rogers, Lab Chip, 2019, 19, 1545.

81. E. P. Dutkiewick, K. T. Hsieh, Y. S. Wang, H. Y. Chiu, and P. L. Urban, Clin. Chem., 2016, 62, 1120.

82. O. O. Adewole, G. E. Erhabor, T. O. Adewole, A. O. Ojo, H. Oshokoya, L. M. Wolfe, and J. E. Prenni, Proteomic Clin. Appl., 2016, 10, 547.

83. M. M. Raiszadeh, M. M. Ross, P. S. Russo, M. A. Schaepper, W. Zhou, J. Deng, D. Ng, A. Dickson, C. Dickson, M. Strom, C. Osorio, T. Soeprono, J. D. Wulfkuhle, E. F. Petricoin, L. A. Liotta, and W. M. Kirsch, J. Proteome Res., 2012, 11, 2127.

84. G. Cizza, A. H. Marques, F. Eskandari, I. C. Christie, S. Torvik, M. N. Silverman, T. M. Phillips, and E. M. Sternberg, Biol. Psychiatry, 2008, 64, 907.

85. L. C. Clark Jr and C. Lyons, Ann. N. Y. Acad. Sci., 1962, 102, 29.

86. X. He, T. Xu, Z. Gu, W. Gao, L. P. Xu, T. Pan, and X Zhang, Anal. Chem., 2019, 91, 4296.

87. A. J. Bandodkar, P. Butruf, J. Choi, K. Lee, Y. Sekine, J. T. Reeder, W. J. Jeang, A. J. Aranyosi, S. P. Lee, J. B. Model, R. Ghaffari, C. J. Su, J. P. Leshock, T. ray, A. Verrillo, K. Thomas, V. Krishnamurthi, S. Han, J. Kim, S. Krishnan, T. Hang, and J. A. Rogers, Sci. Adv., 2019, 5, eaav3294.

88. J. Kim, J. R. Sempionatto, S. Imani, M. C. Hartel, A. Barfidokht, G. Tang, A. S. Campbell, P. P. Mercier, and J. Wang, Adv. Sci., 2018, 5, 1800880.

89. B. Gao, A. Elbaz, Z. he, Z. Xie, H. Xu, S. Liu, E. Su, H. Liu, and Z. Gu, Adv. Mater. Technol., 2018, 3, 1700308.

90. Y. Lei, W. Zhao, Y. Zhang, Q. Jiang, Jr H. He, A. J. Baeumner, O. S. Wolfbeis, Z. L. Wang, K. N. Salama, and H. N. Alshareef, Small, 2019, 15, 1901190.
91. Y. J. Hong, H. Lee, J. Kim, M. Lee, H. J. Choi, T. Hyeon, and D. H. Kim, Adv. Funct. Mater, 2018, 28, 1805754.

92. D. Kinnamon, R. Ghanta, K. C. Lin, S. Muthukumar, and S. Prasad, Sci. Rep., 2017, 7, 13312.

93. E. V. Karpova, E. V. Shcherbacheva, A. A. Galushin, D. V. Vokhmyanina, E. E. Karyakina, and A. A. Karyakin, Anal. Chem., 2019, 91, 3778.

94. J. R. Sempionatto, T. Nakagawa, A. Pavinatto, S. T. Mensah, S. Imani, P. Mercier, and J. Wang, Lab Chip, 2017, 17, 1834.

95. S. Wang, Y. Wu, Y. Gu, T. Li, H. Luo, L. H. Li, Y. Bai, L. Li, L. Liu, Y. Cao, H. Ding, and T. Zhang, Anal. Chem., 2017, 89, 10224.

96. S. Imani, A. J. Bandodkar, A. M. V. Mohan, R. Kumar, S. Yu, J. Wang, and P. P. Mercier, Nat. Commun., 2016, 7, 11650.

97. M. Parrilla, R. Cánovas, I. Jeerapan, F. J. Andrade, and J. Wang, Adv. Healthcare Mater, 2016, 5, 996.

98. L. Wang, L. Wang, Y. Zhang, J. Pan, S. Li, X. Sun, B. Zhang, and H. Peng, Adv. Funct. Mater., 2018, 28, 1804456.

99. C. H. Chen, P. W. Lee, Y. H. Tsao, and Z. H. Lin, Nano Energy, 2017, 42, 241.

100. H. Y. Y. Nyein, L. C. Tai, Q. P. Ngo, M. Chao, G. B. Zhang, W. Gao, M. Bariya, J. Bullock, H. Kim, H. M. Fahad, and A. Javey, ACS Sens., 2018, 3, 944.

101.J. Choi, A. J. Bandodkar, J. T. Reeder, T. R. Ray, A. Turnquist, S. B. Kim, N. Nyberg, A. Hourlier-Fargette, J. B. Model, A. J. Aranyosi, S. Xu, R. Ghaffari, and J. A. Rogers, ACS Sens., 2019, 4, 379.

102. S. Anastasova, B. Crewther, P. Bembnowicz, V. Curto, H. M. D. Ip, B. Rosa, and G. Z. Yang, Biosens. Bioelectron., 2017, 93, 139.

103. T. Shay, M. D. Dickey, and O. D. Velev, Lab Chip, 2017, 17, 710 .

104. Y. Sekine, S. B. Kim, Y. Zhang, A. J. Bandodkar, S. Xu, J. Choi, M. Irie, T. R. Ray, P. Kohli, N. Kozai, T. Sugita, Y. Wu, K. Lee, K. T. Lee, R. Ghaffari, and J. A. Rogers, Lab Chip, 2018, 18, 2186.

105. A. Hauke, P. Simmers, Y. R. Ojha, B. D. Cameron, R. Ballweg, T. Zhang, N. Twine, M. Brothers, E. Gomez, and J. Heikenfeld, Lab Chip, 2018, 18, 3750.

106. T. C. Boysen, S. Yanagawa, F. Sato, and K. Sato, J. Appl. Physiol. Respir. Environ. Exerc. Physiol., 1984, 56, 1302.

107.L. C. Tai, W. Gao, M. Chao, M. Bariya, Q. P. Ngo, Z. Shahpar, H. Y. Y. Nyein, H. Park, J. Sun, Y. Jung, E. Wu, H. M. Fahad, D. H. Lien, H. Ota, G. Cho, and A. Javey, Adv. Mater., 2018, 30, 1707442.

108. T. Tsuda, S. Noda, S. Kitagawa, and T. Morishita, Biomed. Chromatogr., 2000, 14, 505.

109. T. Hirokawa, H. Okamoto, Y. Gosyo, T. Tsuda, and A. R. Timerbaev, Anal. Chim. Acta, 2007, 581, 83.

110.E. P. Dutkiewicz, J. D. Lin, T. W. Tseng, Y. S. Wang, and P. L. Urban, Anal. Chem., 2014, 86, 2337.

111.E. P. Dutkiewicz, H. Y. Chiu, and P. L. Urban, J. Mass Spectrom., 2015, 50, 1321.

112.E. P. Dutkiewicz, H. Y. Chiu, and P. L. Urban, Anal. Chem., 2017, 89, 2664.

113. M. Tsunoda, M. Hirayama, T. Tsuda, and K. Ohno, Clin. Chim. Acta, 2015, 442, 52.

114.D. F. Brebner, and D. McK. Kerslake, J. Physiol., 1964, 175, 295

115. W. C. Randall, and C. N. Peiss, J. Invest. Dermatol., 1957, 28,435

116. C. N. Peiss, W. C. Randall, and A. B. Hertzman, J. Invest. Dermatol., 1956, 26, 459. 
117. S. Lin, B. Wang, Y. Zhao, R. Shih, X. Cheng, W. Yu, H. Hojaiji, H. Lin, C. Hoffman, D. Ly, J. Tan, Y. Chen, D. D. Carlo, C. Milla, and S. Emaminejad, ACS Sens., 2020, 5, 93.

118. K. Hayasaka, H. Matsui, Y Takeda, R. Shiwaku, Y. Tanaka, T. Shiba, D. Kumaki, and S. Tokito, Adv. Electron. Mater, 2017, 3, 1700208.

119. J. Kwon, Y. Takeda, R. Shiwaku, S. Tokito, K. Cho, and S. Jung, Nat. Commun., 2019, 10, 54.

120.L. Li, L. Pan, Z. Ma, K. Yan, W. Cheng, Y. Shi, and G. Yu, Nano Lett., 2018, 18, 3322.

121.E. Bihar, S. Wustoni, A. M. Pappa, K. N. Salama, D. Baran, and S. Inal, npj Flexible Electron., 2018, 2, 30.

122. B. Weng, A. Morrin, R. Shepherd, K. Crowley, A. J. Killard, P. C. Innis, and G. G. Wallance, J. Mater. Chem B, 2014, 2, 793.

123. J. Li, F. Rossignol, and J. Macdonald, Lab Chip, 2015, 15, 2538.

124. V. Beni, D. Nilsson, P. Arven, P. Norberg, G. Gustafsson, and A. P. F. Turner, ECS J. Solid State Sci. Technol., 2015 4, S3001.

125.P. Ihalainen, A. Määttänen, and N. Sandler, Int. J. Pharm., 2015, 494, 585.

126.L. Gonzalez-Macia, A. Morrin, M. R. Smyth, and A. J. Killard, Analyst, 2010, 135, 845.

127.D. Shiokawa, K. Izumi, R. Sugano, T. Sekine, T. Minami, D. Kumaki, and S. Tokito, J. J. Appl. Phys., 2017, 56, 05EA01.

128. M. Bariya, Z. Shahpar, H. Park, J. Sun, Y. Jung, W. Gao, H. Y. Y. Nyein, T. S. Liaw, L. C. Tai, Q. P. Ngo, M. Chao, Y. Zhao, M. Hettick, G. Cho, and A. Javey, ACS Nano, 2018,
12, 6978.

129. K. Izumi, Y. Yoshida, and S. Tokito, Flexible and Printed Electronics, 2018, 3, 15011.

130. K. Izumi, Y. Yoshida, and S. Tokito, IEEE-ICEP, 2017, 16932399.

131.H. Nakamura, Y. Yoshida, and K. Izumi, IEEE-ICEP, 2017, 16932476.

132. K. Izumi, Y. Yoshida, and S. Tokito, Flexible and Printed Electronics, 2017, 2, 24003.

133. S. Khan and L. Lorenzelli, IEEE Sens. J., 2015, 15, 3164.

134. Y. Takeda, Y. Yoshimura, R. Shiwaku, K. Hayasaka, T. Sekine, T. Okamoto, H. Matsui, D. Kumaki, Y. Katayama, and S. Tokito, Adv. Electron. Mater, 2018, 4, 1700313.

135. K. Fukuda, Y. Yoshimura, T. Okamoto, Y. Takeda, D. Kumaki, Y. Katayama, and S. Toktio, Adv. Electron. Mater, 2015, $1,1500145$.

136. K. Izumi, Y. Yoshida, and S. Tokito, J. J. Appl. Phys., 2017, 56, 05EA03.

137. A. Miyamoto, S. Lee, N. F. Cooray, S. Lee, M. Mori, N. Matsuhisa, H. Jin, L. Yoda, T. Yokota, A. Itoh, M. Sekino, H. Kawasaki, T. Ebihara, M. Amagai, and T. Someya, Nat. Nanotech., 2017, 12, 907.

138.D. P. Rose, M. E. Ratterman, D. K. Griffin, L. Hou, N. Kelley-Loughnane, R. R. Naik, J. A. Hagen, I. Papautsky, and J. Heikenfeld, IEEE Trans. Biomed. Eng., 2015, 62, 1457.

139. Y. Khan, M. Garg, Q. Gui, M. Schadt, A. Gaikwad, D. Han, N. A. D. Yamamoto, P. Hart, R. Welte, W. Wilson, S. Czarnecki, M. Poliks, Z. Jin, K. Ghose, F. Egitto, J. Turner, and A. C. Arias, Adv. Funct. Mater, 2016, 26, 8764. 